\title{
LICENCIATURA EM QUÍMICA DA UFC: PERFIL SÓCIO-ECONÔMICO, EVASÃO E DESEMPENHO DOS ALUNOS
}

\author{
Selma Elaine Mazzetto* e Claudia Christina Bravo e Sá Carneiro \\ Departamento de Química Orgânica e Inorgânica, Universidade Federal do Ceará, CP 12200, 60455-760 Fortaleza - CE
}

Recebido em 11/6/01; aceito em 15/4/02

\begin{abstract}
STUDENT'S SOCIAL AND ECONOMIC PROFILE, DROPOUT IN THE CHEMISTRY COURSE AT UFC. This paper describes the studies of the performance and the efficiency of the Degree in Chemistry (nocturne) course at the UFC. The study embraces the period of its foundation (1995) until the current days. In general, the course has enhanced its efficiency, with an evident improvement presented by the students, which are more confident with strong indicative of better social prestige.
\end{abstract}

Keywords: students' social and economic profile; undergraduate course; undergraduate evaluation.

\section{INTRODUÇÃO}

A educação é hoje uma prioridade no mundo. De acordo com suas características históricas, diferentes países promovem reformas em seus sistemas educacionais, com a finalidade de torná-los mais eficientes para enfrentarem a revolução tecnológica que está ocorrendo no processo produtivo e seus desdobramentos políticos, sociais e éticos ${ }^{1}$.

Pesquisas sobre formação de professores no Brasil, em especial sobre as licenciaturas, têm levantado problemas vividos por tais cursos, que ainda não foram resolvidos. Apesar de criados no país nos anos trinta, o modelo de formação nos cursos de licenciatura freqüentemente ainda se inspira na fórmula " $3+1$ ", ou seja, disciplinas de conteúdos específicos com duração de três anos, seguidas das disciplinas de cunho pedagógico com um ano de duração, caracterizando a desarticulação teoria/prática². Situação como esta resulta em grandes lacunas na formação dos licenciados.

Por outro lado, as licenciaturas, nas Universidades públicas ou privadas, de acordo com $\mathrm{Gatti}^{3}$, não ocupam lugar privilegiado nas políticas daquelas instituições e, raramente, merecem atenção de projetos. Entre professores e alunos do ensino superior, por exemplo, há uma tendência em menosprezar as questões do ensino e a formação para o exercício do magistério ${ }^{3}$.

Na tentativa de melhorar este e outros pontos relevantes na questão dos profissionais da educação, fundamentos legais foram criados com a implantação da Lei de Diretrizes e Bases (Lei n 9394/96). Em seu texto, entre outras exigências, a LDB determina que qualquer tipo de formação docente deva ter no mínimo $300 \mathrm{~h}$ de prática de ensino, caracterizando esta disciplina como o eixo formador e articulador na formação dos professores.

A Universidade Federal do Ceará - UFC mantém o curso de Química alocado junto ao Centro de Ciências, com as modalidades Licenciatura e Bacharelado, reconhecidas em 1961, pelo Decreto Lei ${ }^{\circ}$ $3866{ }^{4}$. Em 1995, a UFC criou o curso de Química noturno na modalidade Licenciatura, como alternativa proposta pela Universidade, para a redução de pessoal, determinada pelo governo Collor. O curso oferece 40 vagas anuais (oriundas do vestibular) com um total de 167 créditos $^{5}$. As características principais do curso estão direcionadas para a formação de professores para atuarem no ensino fundamental e mé-

\footnotetext{
*e-mail: selma@ufc.br
}

dio, preenchendo a carência regional existente nos dias atuais. A estes estudantes, de acordo com o projeto pedagógico do curso, oferece-se uma formação de conteúdos específicos e pedagógicos (teórica/prática), com ênfase na atuação das necessidades do currículo secundário ${ }^{6}$.

$\mathrm{Na}$ época da sua implantação houve opiniões contrárias por parte dos docentes e do Centro de Ciências, argumentando problemas referentes a condições de segurança no campus, falta de estrutura e de corpo docente disponível. Em contrapartida, o MEC (Ministério da Educação e Cultura) reiterava sua opinião sobre a necessidade da abertura dos cursos (no mesmo período três novas licenciaturas foram implantadas simultaneamente: Química, Física e Biologia) justificando que os estudantes deveriam ocupar este espaço noturno; que seria contemplada uma fração de estudantes impossibilitados de estudar no período diurno e a promessa de contratação de professores exclusivos para ensinar no referido curso.

Cinco anos após sua implantação percebe-se que, de fato, o curso tem atingido alguns de seus objetivos básicos. No entanto, na tentativa de melhor compreender o estado atual da Licenciatura em Química da UFC, sob os olhares de seus alunos, foi realizado um estudo no período entre 1998/2 a 2000/1, baseado em depoimentos obtidos por entrevistas semi-estruturadas, não estruturadas e rela$\operatorname{tos}^{7}$. A análise das informações obtidas serviu para reiterar o que outras pesquisas do gênero demonstraram ${ }^{3,7}$ : o grau de insatisfação dos licenciados quanto à sua formação é alto. Os alunos destacaram, entre outros pontos, problemas com a estrutura curricular, desarticulação de disciplinas específicas com as pedagógicas; infraestrutura inadequada, principalmente para o curso noturno (biblioteca não funciona em tempo integral, xerox fechado, insuficiência de material didático, etc); formação afastada da realidade do ensino básico; formação inadequada de professores (falta, muitas vezes, a consciência de que estão formando futuros professores).

Percebe-se, então, que os alunos, futuros professores de química, são, de certo modo, conscientes de sua realidade, uma realidade que não é única, mas que precisa ser repensada, apesar dos avanços que já se fizeram notar paulatinamente. Naturalmente, as discussões voltadas à reestruturação das Licenciaturas no Ceará e no Brasil têm levado a mudanças consideráveis. Movimentos de educadores, em especial desenvolvidos pela Associação Nacional de Formação do Profissional da Educação - ANFOPE, têm desencadeado discussões pertinentes nos últimos anos ${ }^{8}$.

Considerando as novas alterações legais e na tentativa de verificarmos o andamento do curso, bem como o desempenho dos estudan- 
tes que optaram por cursar Licenciatura em Química (noturno) pela UFC, fez-se um estudo sobre os cinco primeiros anos de seu funcionamento, abordando aspectos como perfil socioeconômico dos estudantes; evasão; desempenho no vestibular; tempo gasto para a conclusão do curso e uma investigação referente à continuidade de estudos desses estudantes nos cursos de pós-graduação em Química na referida Instituição (a UFC oferece, dentre outros cursos de pós-graduação, Mestrado e Doutorado nas áreas de Química Orgânica e Inorgânica).

Os resultados obtidos neste estudo nos permitirão, em médio prazo, traçar um paralelo entre os estudantes em curso na legislação anterior e aqueles que estão vinculados às novas diretrizes governamentais (regime de $300 \mathrm{~h}$ de prática de ensino) ${ }^{9}$, por exemplo, estabelecidas pela LDB. O estudo também permitirá a verificação do desempenho destes estudantes no transcorrer de suas atividades como graduandos e, dentre outros aspectos, a viabilidade na manutenção deste curso em função da procura e do seu desempenho.

\section{METODOLOGIA}

Para o referido estudo, optou-se pela pesquisa a documentos e dados provenientes de vários setores da UFC, na busca de confrontálos e analisá-los, para a elaboração de um perfil fidedigno.

$\mathrm{O}$ estudo abrangeu as diversas categorias de acesso praticadas pela $\mathrm{UFC}^{10}$, a saber: Vestibular, Transferência, Admissão por Convênio, Admissão de Graduado, Mudança de Curso e Reopção ${ }^{11}$. Os dados referentes à entrada de estudantes oriundos de vestibular, bem como seus respectivos perfis socioeconômicos, nos foram fornecidos pela Comissão do Concurso do Vestibular (CCV) e pelo Núcleo de Processamento de Dados (NPD)/UFC, respectivamente. No perfil socioeconômico foram avaliados itens referentes à trajetória escolar do aluno; renda familiar; classificação no vestibular e nível de instrução dos pais, a partir de questionário preenchido pelos candidatos quando da inscrição dos mesmos ao vestibular. Conceituou-se como evasão toda e qualquer forma de saída do estudante do curso, que não tenha sido pela diplomação.

Ao NPD também foi solicitado um levantamento referente aos estudantes que ingressaram no período entre 1995 a 2000 no curso de Licenciatura em Química (noturno) via admissão de graduado. Tanto para esta modalidade de entrada quanto para mudança de curso, a Pró-reitoria de Planejamento disponibiliza semestralmente um número de vagas (variável entre os cursos oferecidos pela UFC) e, após análise criteriosa do currículo dos pleiteantes, há uma classificação dos mesmos para preenchimento destas vagas. Qualquer profissional graduado nas mais diferentes áreas de atuação pode solicitar sua entrada via Admissão de Graduado.

Finalmente, os resultados envolvendo o ingresso destes estudantes nos cursos de pós-graduação (as análises se restringiram ao ingresso nos cursos de Mestrado) no Departamento de Química Orgânica e Inorgânica, nos foram fornecidos pela Secretaria de Pós-graduação do Departamento de Química Orgânica e Inorgânica - UFC. Neste quesito, fez-se um levantamento não só dos estudantes oriundos do curso de Licenciatura, como também daqueles que ingressaram nos programas de pós-graduação provenientes dos cursos de Bacharelado em Química e Química Industrial.

Os dados foram compilados e analisados utilizando-se o pacote estatístico SPSS e fazendo-se seu tratamento através de uma análise descritiva. A interpretação deu-se á luz da literatura especializada e da reflexão crítica.

\section{RESULTADOS E DISCUSSÃO}

Em uma primeira análise, traçou-se o perfil dos estudantes que optaram pelo curso de Licenciatura em Química (noturno), no perí- odo de 1995 a 2000. Posteriormente, a estes dados foram acrescidas informações constantes do registro acadêmico individual de cada estudante.

Neste estudo, em particular, após prévia análise dos dados, constatamos claramente, segundo os dados disponibilizados pela UFC, duas classes de estudantes com faixas etárias e perfis diferenciados, razão pela qual optamos em subdividi-las em duas categorias: idade média entre 17 - 25 anos e 26 - 42 anos. Mesmo considerando dados disponíveis na Internet ${ }^{12}$, os quais estimam que a idade média de conclusão da graduação em Química no Brasil é de 26,5 anos e que a idade média de ingresso destes estudantes é de 21,5 anos, nosso interesse principal foi direcionado para observar que tipo de estudante se interessa pelo curso de Licenciatura em Química na UFC, não havendo, na nossa opinião, a necessidade de enquadrá-los em uma faixa etária de entrada ou término de curso.

A primeira classe distinguida, que retém os maiores percentuais (percentual médio de $64 \%$ no período analisado), refere-se a estudantes mais jovens: idade entre 17 e 25 anos; em sua maioria (90\%) residentes em Fortaleza; $48 \%$ oriundos de escolas privadas, enquanto que $31 \%$ de escolas públicas, $19 \%$ concluíram a maior parte de seus estudos ( $1^{\circ}$ e $2^{\circ}$ graus) em escolas privadas e apenas $2 \%$ obtiveram sua conclusão em escolas comunitárias. São solteiros em sua maioria e obtiveram sucesso entre a primeira (60\%) e a segunda (19\%) tentativas no vestibular. Categorizamos estes estudantes como não participantes efetivos da vida econômica familiar, pois, apesar da maioria trabalhar (57\%), estes recebem ajuda financeira da família ou de outras pessoas, não sendo, portanto, responsáveis pelo próprio sustento; $58 \%$ nunca freqüentaram cursinho, fato justificado por acharem que a formação prévia recebida foi suficiente.

A segunda categoria verificada (percentual médio de $36 \%$ no período investigado) é composta por estudantes com faixa etária superior à esperada para um "calouro", ou seja: idade entre 26 e 42 anos; também em sua maioria residentes em Fortaleza. Destes, $82 \%$ são oriundos de escolas públicas e obtiveram sucesso entre a terceira e quarta tentativas no vestibular. Para essa categoria, quase que a totalidade participa efetivamente da vida econômica familiar, contribuindo para o sustento da mesma. $89 \%$ são casados e $60 \%$ nunca freqüentaram cursinho, alegando duas justificativas com maiores percentuais: falta de condições financeiras e/ou acharem poder estudar sozinhos.

Analisando os resultados do perfil socioeconômico desta segunda categoria, entendemos que neste percentual estão englobados candidatos que querem se profissionalizar, mas precisam trabalhar durante o dia e candidatos que, pelos mais diferentes motivos, voltaram para a Universidade com o objetivo de melhorarem suas qualificações profissionais, ou mesmo, por estarem lecionando em escolas de ensino médio e portarem diplomas de educação superior, necessitam, por força da LDB (Art. 62), de uma formação pedagógica para poderem se dedicar à profissão de professor.

Por outro lado, não podemos deixar de considerar que nesta categoria há uma população de estudantes que iniciaram suas atividades acadêmicas com idade mais avançada ${ }^{13}$. Segundo pesquisas realizadas pelo Instituto Nacional de Estudos e Pesquisas Educacionais $(\text { INEP })^{12}$, os estudantes brasileiros ingressam tarde no ensino superior. A idade média dos alunos que estão no sistema é de 25 anos, quando, se todos iniciassem seu curso aos 18 ou 19 anos, ela deveria ser 21 ou, no máximo 22 anos, levando-se em conta o prazo médio de cinco anos para a conclusão do curso de graduação.

Um fato interessante nos chamou a atenção: considerando as novas diretrizes da LDB e o fato da necessidade de um grande percentual de professores do ensino básico precisarem obter nível superior completo até o ano de 2007, era de se esperar um acréscimo do número de candidatos (via vestibular) com faixa etária mais avançada, concorrendo a estas vagas oferecidas, especialmente no noturno. 
Na verdade, observa-se um comportamento inverso na categoria de entrada "Vestibular", ou seja, analisando o período entre 19962000, dentre os candidatos inscritos no vestibular, há um decréscimo no percentual para aqueles com faixa etária superior a 26 anos, decaindo de 54\% em 1996 para 18\% em 2000 (Figura 1). Para o mesmo período percebe-se, também, uma tendência de aumento na categoria "Admissão de Graduado" (Tabela 1). São vários os argumentos que podem tentar esclarecer tal inversão de comportamento, como elucidaremos a seguir.

É necessário esclarecer que, com a aprovação da LDB, houve uma ampliação dos debates sobre a formação dos professores nas universidades brasileiras. Esta discussão, frente às novas demandas educacionais decorrentes das exigências dos avanços científicos e tecnológicos do mundo globalizado, sob a influência das variadas alterações na estrutura jurídico-legal da educação, das conseqüentes mudanças na escola básica e na educação superior, levou, provavelmente, à maior procura pela profissão docente.

$\mathrm{O}$ fato é que os desafios da sociedade atual exigem qualificações cada vez maiores, ampliando-se as necessidades educacionais da população. Neste cenário, cresce a importância dos cursos de graduação. Assim, a competitividade no ingresso aos cursos tende a crescer.

Realmente, é evidente o considerável aumento das matrículas nos cursos superiores, em especial a partir dos anos noventa ${ }^{14}$. Entretanto, deve ser verificado que a oferta do ensino superior, embora haja triplicado a partir dos anos setenta ${ }^{8}$, é ainda insuficiente para fazer face à demanda oriunda da grande expansão do Ensino Médio $^{14}$. Sem dúvida, o ensino superior brasileiro entrou numa fase de crescimento acelerado e de diversificação.

Tais tendências de crescimento são confirmadas pelos resultados do Censo da Educação Superior ${ }^{12}$, realizado pelo INEP, que si-

\section{FAIXA ETÁRIA DOS CANDIDATOS INSCRITOS}

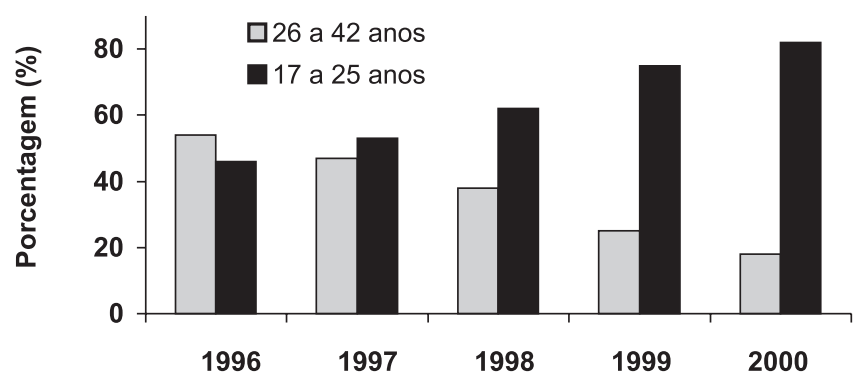

Figura 1. Percentual de faixa etária dos candidatos inscritos no vestibular, abrangendo o período entre 1996-2000 nalizaram uma nova dinâmica de desenvolvimento do sistema brasileiro de educação superior, caracterizada, dentre outros aspectos, pela tendência na aceleração da expansão da matrícula na graduação a partir de 1994 e, mais acentuadamente, desde 1996 observando-se uma redução das desigualdades regionais na oferta de vagas, com participação preponderante do setor público nas Regiões Norte e Nordeste; aumento da participação da matrícula noturna na oferta de vagas nas IFES, especialmente na Região Nordeste; aumento de concluintes da graduação, de forma mais acelerada a partir de 1996, levando-se em conta o prazo médio de cinco anos para conclusão de curso de graduação e melhoria na qualificação docente.

No entanto, o número de vagas não supre ainda as necessidades, em particular, no estado do Ceará, no que tange aos cursos de Licenciatura em Química (existem apenas três cursos de Licenciatura em Química no Estado). Assim, o estudante de maior faixa etária pode estar sendo excluído do curso por não apresentar condições de competitividade com os mais jovens, que, entre vários fatores, têm maiores possibilidades em se prepararem para o concurso vestibular.

Dando prosseguimento ao estudo, verificou-se que, ao contrário do observado por algumas instituições de ensino ${ }^{15}$, no curso de Química da UFC, a proporção de alunos provenientes do sistema público de ensino sofreu uma diminuição substancial, em torno de 70 a 80\% registrados no triênio 1995-1997 para cerca de 30 a 40\% para o período entre 1998-2000. Esta é uma ocorrência que parece sustentar uma hipótese de aumento do prestígio do curso de Licenciatura em Química, pois o aluno, à procura de uma previsível melhor formação, opta pelas escolas da rede privada de ensino.

As estatísticas divulgadas pelo Governo do Estado do Ceará ${ }^{16}$ corroboram essa hipótese: a rede pública de ensino médio cresceu no estado, 25\% no período de 1996-1999 e é hoje responsável por $71 \%$ das matrículas, sendo $54 \%$ em escolas estaduais, $14 \%$ em escolas municipais e $3 \%$ em escolas federais. A rede privada, no mesmo período, retraiu seu número de matrículas em cerca de $3 \%$ e atende hoje somente a $29 \%$ da procura. Sendo assim, torna-se mais significativa a mudança de perfil dos estudantes que procuram o curso noturno de Química da UFC.

Considerando o fato de que um grande percentual dos ingressantes no curso de Licenciatura em Química tem obtido sua formação prévia em escolas particulares, ao contrário da tendência geral, tentamos verificar dois parâmetros importantes na abordagem do perfil socioeconômico destes calouros: renda familiar média do estudante e nível de formação dos pais, na esperança de obtermos respostas mais viáveis a esse comportamento.

Segundo dados fornecidos no cadastro dos estudantes, a renda familiar do estudante de Licenciatura em Química (noturno) ultrapassa seis salários mínimos, chegando a nove, em alguns casos, sofrendo um pequeno declínio (em torno de 10\%) no biênio 1999-

Tabela 1. Formas de entrada pelos estudantes da UFC, durante o período entre 1995-2000

\begin{tabular}{|c|c|c|c|c|c|c|c|}
\hline \multirow[b]{2}{*}{ Ano de entrada } & \multicolumn{6}{|c|}{ Tipo de Ingresso ${ }^{(a)}$} & \multirow[b]{2}{*}{ TOTAL } \\
\hline & Vestibular & Reopção & $\begin{array}{l}\text { Admissão } \\
\text { Graduado }\end{array}$ & $\begin{array}{c}\text { Mudança } \\
\text { Curso }\end{array}$ & $\begin{array}{c}\text { Transf. } \\
\text { Lei }\end{array}$ & $\begin{array}{l}\text { Transf. } \\
\text { Regular }\end{array}$ & \\
\hline 1995 & 06 & - & - & 03 & 02 & - & 11 \\
\hline 1996 & 26 & 06 & 03 & - & 02 & 01 & 38 \\
\hline 1997 & 35 & 05 & 16 & 02 & - & 02 & 60 \\
\hline 1998 & 40 & - & 05 & 04 & - & 03 & 52 \\
\hline 1999 & 40 & - & 16 & 11 & - & 03 & 70 \\
\hline 2000 & 40 & - & 03 & 11 & - & 06 & 60 \\
\hline
\end{tabular}

(a) Fonte: Pró-Reitoria de Planejamento - Coordenadoria de Estatística e Informática-UFC 
2000. Com relação ao grau de instrução dos pais, observamos um pequeno, mas progressivo aumento da fração daqueles que são filhos de pais com formação de terceiro grau, conforme ilustra a Figura 2. Verificamos ainda um substancial e também progressivo aumento da percentagem de estudantes cujos pais concluíram a escola média. Mais uma vez os indicadores sinalizam para um crescimento do prestígio social do curso noturno de Química da UFC.

Um outro aspecto a ser considerado no estudo em questão diz respeito a um dos problemas mais graves detectados nos cursos de Licenciatura do país, a evasão dos seus estudantes. Um percentual significativo dos ingressados não permanece até a conclusão do cur-

\section{GRAU DE ESCOLARIDADE DOS PAIS}

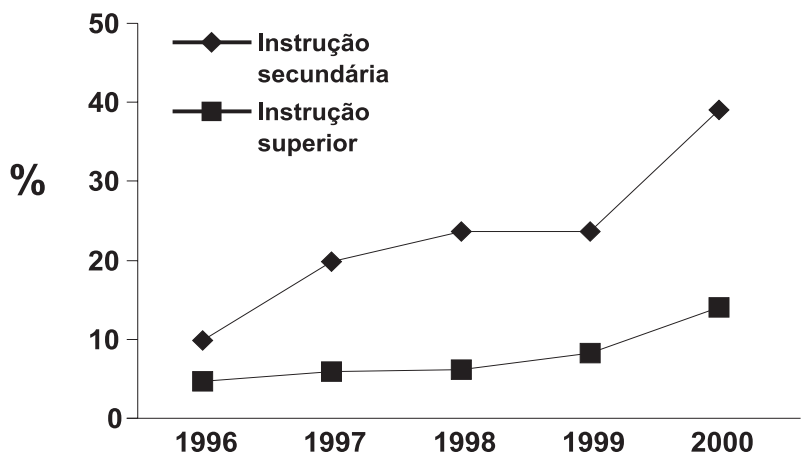

Figura 2. Nível de instrução dos pais, entre o período de 1996 a 2000 so, outros utilizam as opções que as Universidades oferecem, como mudança de curso e transferência.

Estes tipos de evasão podem ser atribuídos, talvez, ao pouco interesse dos ingressados em permanecerem no curso de entrada (muitas vezes a opção no vestibular não retrata com fidelidade a verdadeira vontade do candidato) e/ou, em muitos casos, por optarem por cursos com menor concorrência no vestibular para posterior tentativa de mudança de curso. No caso particular do curso de Licenciatura em Química (noturno) da UFC, no período analisado, a relação candidato/vaga manteve-se em 1,3:1,0 no período de 1995/1997 e 2,5:1,0 entre 1998/2000.

Por outro lado, o Censo do Ensino Superior ${ }^{12}$ revela que a sobra de vagas é predominante nos cursos de Licenciatura, pouco atraentes para quem está ingressando no ensino superior. O desinteresse pelas áreas de Licenciatura pode estar sendo influenciado pela baixa qualidade do ensino e pelo surgimento de novas carreiras, sinalizando que estes cursos precisam melhorar sua qualidade, já que faltam professores qualificados para dar aulas no ensino fundamental e no ensino médio. Cerca de 825 mil professores desses dois níveis de ensino não possuem formação superior.

Percebe-se, entretanto, que este panorama parece estar em mutação nos últimos anos, tendo em vista que, no caso particular do curso de Licenciatura em Química noturno da UFC, a relação candidato/vaga tem aumentado. No vestibular 2001 da Instituição, por exemplo, a referida relação alcançou o número de três candidatos para uma vaga. Tais indicativos pendem para a reafirmação do fato de que o curso está melhorando em qualidade e prestígio. Abordando estes aspectos, fez-se o acompanhamento do desempenho destes (formados e evadidos) durante o período 1995-2000, Tabela 2.

Tabela 2. Saídas ocorridas no curso de Licenciatura em Química (noturno), por turma de alunos ingressos a cada ano, no período entre 1995 a 2000

\begin{tabular}{|c|c|c|c|c|c|c|c|}
\hline \multirow{2}{*}{$\begin{array}{l}\text { Ano de } \\
\text { Ingresso }\end{array}$} & \multirow{2}{*}{$\begin{array}{l}\mathrm{N}^{\circ} \text { de alunos } \\
\text { Ingressantes }\end{array}$} & \multirow[t]{2}{*}{ Situação } & \multicolumn{5}{|c|}{$\mathrm{N}^{\circ}$ de anos após o ingresso } \\
\hline & & & 1 & 2 & 3 & 4 & 5 \\
\hline \multirow[t]{3}{*}{1995.1} & 06 & 1- Matriculado & $100,0 \%$ & $83,3 \%$ & $66,7 \%$ & $16,7 \%$ & \\
\hline & & 2- Diplomado & & & $16,7 \%$ & $50,0 \%$ & $66,7 \%$ \\
\hline & & 3- Evadido & & $16,7 \%$ & $16,7 \%$ & $33,3 \%$ & $33,3 \%$ \\
\hline \multirow[t]{2}{*}{1995.2} & 05 & 1- Matriculado & $80,0 \%$ & $80,0 \%$ & $80,0 \%$ & $80,0 \%$ & \\
\hline & & 2- Evadido & $20,0 \%$ & $20,0 \%$ & $20,0 \%$ & $20,0 \%$ & \\
\hline \multirow[t]{3}{*}{1996.1} & 18 & 1- Matriculado & $91,1 \%$ & $82,4 \%$ & $47,1 \%$ & $35,3 \%$ & \\
\hline & & 2- Diplomado & & & $17,6 \%$ & $17,6 \%$ & \\
\hline & & 3- Evadido & $5,9 \%$ & $17,6 \%$ & $35,3 \%$ & $47,1 \%$ & \\
\hline \multirow[t]{2}{*}{1996.2} & 20 & 1- Matriculado & $100,0 \%$ & $75,0 \%$ & $65,0 \%$ & & \\
\hline & & 2- Evadido & & $25,0 \%$ & $35,0 \%$ & & \\
\hline \multirow[t]{3}{*}{1997.1} & 49 & 1- Matriculado & $89,8 \%$ & $63,3 \%$ & $53,1 \%$ & & \\
\hline & & 2- Diplomado & & $8,2 \%$ & $12,2 \%$ & & \\
\hline & & 3- Evadido & $10,2 \%$ & $28,6 \%$ & $34,7 \%$ & & \\
\hline \multirow[t]{3}{*}{1997.2} & 11 & 1- Matriculado & $81,8 \%$ & $63,6 \%$ & & & \\
\hline & & 2- Diplomado & $9,1 \%$ & $9,1 \%$ & & & \\
\hline & & 3- Evadido & $9,1 \%$ & $27,3 \%$ & & & \\
\hline \multirow[t]{2}{*}{1998.1} & 49 & 1- Matriculado & $93,9 \%$ & $87,8 \%$ & & & \\
\hline & & 2- Evadido & $6,1 \%$ & $12,2 \%$ & & & \\
\hline \multirow[t]{2}{*}{1998.2} & 03 & 1- Matriculado & $66,7 \%$ & & & & \\
\hline & & 2- Evadido & $33,3 \%$ & & & & \\
\hline \multirow[t]{2}{*}{1999.1} & 50 & 1- Matriculado & $98,0 \%$ & & & & \\
\hline & & 2- Evadido & $2,0 \%$ & & & & \\
\hline
\end{tabular}

Fonte: Pró-Reitoria de Planejamento - Coordenadoria de Estatística e Informática-UFC 
Se analisarmos os 49 alunos ingressantes no período entre 1995 e 1996 (Tabela 2), apenas 7 obtiveram seu diploma no curso de Licenciatura em Química, mostrando que a eficiência do curso neste período foi de $14,3 \%$. Esse percentual de eficiência foi calculado com relação ao número de formandos no período requerido para a formatura, ou seja, entre os semestres 1995.1, 1995.2, $1996.1 \mathrm{e}$ 1996.2, ingressaram um total de 49 estudantes. Considerando o tempo necessário para concluir o curso (oito semestres), todos estes deveriam ter se formado entre o período entre 1998.2 a 2000.1.

Entretanto, apenas sete conseguiram concluir o curso dentro do prazo. Entendemos que, em se tratando de um curso relativamente novo, o cálculo da eficiência utilizando-se apenas quatro semestres de entrada, somando o fato dos mesmos representarem os dois primeiros anos de funcionamento de curso, passa a ser um critério pouco eficaz para retratar a sua atual realidade.

Informações recentes fornecidas pela pró-reitoria de planejamento revelam um significativo crescimento do número de formandos deste curso, por exemplo, no período entre 1999.1 a 2001.130 estudantes obtiveram seus diplomas de Licenciado, o que pode significar um maior empenho dos mesmos em terminar seus cursos para poderem ingressar no mercado de trabalho ou mesmo lá permanecerem, visto estarem pressionados pela LDB. É fato comprovado que muitos de nossos alunos já atuam como docentes com licença provisória. As possibilidades de emprego nas escolas, públicas e particulares, também, têm aumentado, tendo em vista a consciência crescente da importância da educação nos dias atuais. Atualmente 15,69\% dos professores que atuam no Ceará ainda são leigos ${ }^{17}$. Boa parte deles estão se habilitando em nível superior, mediante recursos oriundos do Governo do Estado em convênios com o Banco Mundial, Universidades e congêneres e pelo próprio esforço pessoal do professor.

É sabido que o problema da evasão nos cursos de Química ocorre, de modo geral, no Brasil. Silva e colaboradores ${ }^{18}$, estudando as possíveis causas na evasão dos estudantes de Química na Universidade de Brasília (UnB) observaram que, dentre os alunos ingressantes via vestibular no período compreendido entre 1/85 a 1/89 houve uma eficiência real do curso de $9,5 \%$. Este percentual foi justificado pelo fato dos autores ${ }^{18}$ terem utilizado como percentuais de evasão ${ }^{19}$ : desligamento voluntário, abandono e não cumprimento da condição.

O mesmo também foi observado por Braga ${ }^{15}$ e colaboradores, ao estudarem os fenômenos de evasão $0^{20}$ (reopção, transferência e desistência) e, o desempenho dos estudantes do curso de Química da Universidade Federal de Minas Gerais (UFMG), revelando como resultado, altos percentuais de evasão e repetência. Utilizando os mesmos critérios empregados por Braga ${ }^{15}$ e $\mathrm{Silva}^{18}$ e colaboradores, obtemos uma eficiência real do curso de Licenciatura em Química da UFC de aproximadamente 11,7\%. Embora a evasão seja um grave problema do ensino superior brasileiro, essa questão tem sido freqüentemente negligenciada, tanto por professores como por autoridades universitárias e governamentais. Não raro, a evasão é totalmente debitada aos estudantes, que não teriam base suficiente para acompanhar o curso ou porque não teriam o devido interesse, procurando-o apenas com a perspectiva de transferir-se para outro curso de acesso mais difícil e de futuro mais promissor.

No caso do curso em estudo, os dados referentes ao aumento de sua procura e o número crescente de diplomados parecem desautorizar essa última hipótese. Ademais, o censo do ensino superior ${ }^{12}$ revela que existem cerca de 825 mil professores do ensino médio e do ensino fundamental sem formação superior, que legalmente não poderiam mais atuar após 2007, segundo prescreve a LDB. Como se verá mais adiante, a hipótese da falta de base também parece ser pouco provável, tendo em vista os resultados obtidos nesse trabalho.

Conviria, portanto, que a discussão considerasse também causas de evasão internas ao curso. Mas, antes disso é pertinente apresentar o perfil da evasão no curso noturno de Química - licenciatura da UFC, o que será feito a seguir. Os dados da Tabela 2 evidenciam que, para as turmas de 1995/1997, a evasão após um ano no curso foi de cerca de $10 \%$, em média, índice este que passou para aproximadamente $20 \%$, após dois anos de permanência e alcançou a casa dos $30 \%$, depois de três anos, sugerindo que a evasão final dessas turmas estará na faixa de $40 \%$. Há de se considerar, entretanto, o pequeno número de estudantes associados à maioria dessas turmas, o que não aconselha qualquer generalização ou previsão a partir destes dados, ainda que tal taxa de evasão seja, de fato, preocupante.

Já para as turmas admitidas a partir de 1998, há indícios de que pode se esperar uma redução considerável da evasão. Desconsiderando a turma de 1998/2, constituída de apenas 3 estudantes, o que verificamos é que a evasão reduziu-se para algo em torno de 5\%, após um ano de permanência, e para aproximadamente $10 \%$, após dois anos de permanência, o que prenuncia uma evasão final para essas turmas bem menor - cerca da metade - do que foi projetado no parágrafo anterior para as turmas de 1995/1997. Esse resultado é coerente com o aumento de demanda pelo curso no vestibular.

Procuramos também explorar uma possível correlação entre evasão e perfil sócio-econômico do estudante. Não observamos qualquer diferenciação das taxas de evasão em decorrência, seja do padrão de renda familiar do estudante, seja do grau de instrução de seus pais ou do tipo de escola média - pública ou privada - freqüentada. Tal resultado já era esperado, não só porque reproduz o que já foi observado por Braga e colaboradores ${ }^{15}$ em estudo similar, mas também em razão do fato de o curso estudado ter sido criado recentemente, o que acarreta um pequeno número de evadidos, dificultando que eventuais diferenças observadas tenham significado estatístico.

Convém ainda considerar que se compararmos os percentuais de evasão com os dos cursos de Bacharelado em Química e Química Industrial, ambos do diurno, observa-se que o curso de Licenciatura (noturno) é o que apresenta a menor quantidade de evadidos ${ }^{21}$. Parece que novamente existe a possibilidade do curso em estudo estar melhorando sua eficiência e prestígio. Na verdade, conhecer os reais fatores que influenciam no fenômeno da evasão, requer um trabalho exaustivo e bastante diversificado. Diante dos índices apresentados, concordamos com as conclusões relatadas por Braga e colaboradores ${ }^{15}$ onde, talvez, grande parte da evasão esteja associada à escolha inadequada do curso e às dificuldades internas do mesmo.

Tentando explorar um pouco mais os resultados, fizemos um acompanhamento destes estudantes com relação a seus rendimentos acadêmicos, considerando dois critérios: índice de aprovação e reprovação em duas disciplinas obrigatórias durante o primeiro e segundo períodos do curso, ou seja, Química Geral I e II, respectivamente. Trancamento de matrícula e reprovação por nota foram enquadrados no item reprovação.

Optou-se por escolher o primeiro ano do curso, pois nos pareceu ser o que exerce maiores dificuldades sobre o estudante, por se tratar de um período de adaptação, no qual, inclusive, poder-se-ia verificar se a formação prévia foi adequada para o acompanhamento do curso escolhido e, também, se a opção na escolha da carreira foi a mais adequada.

Os resultados obtidos mostram um percentual médio de reprovação decrescente nestas disciplinas, caindo de 38\% em 1995 para $21,7 \%$ em 2000. Considerando os percentuais apresentados, onde cerca de $60 \%$ dos calouros obtiveram aprovação imediata (ou apenas uma reprovação) nestas disciplinas básicas, entendemos que estes revelam ter uma formação prévia satisfatória ou muito próxima à adequada para o acompanhamento das necessidades do curso.

Podemos correlacionar este decréscimo no percentual de repro- 
vação com a melhoria na formação básica dos estudantes, lembrando que, segundo questionário preenchido pelos candidatos, houve, nos últimos anos, um aumento pela procura dos mesmos em concluírem seus estudos em escolas do sistema privado de ensino, de presumível melhor preparação para o ensino superior. Similarmente ao observado por Braga e colaboradores ${ }^{15}$, nota-se que o número de reprovações é menor em grupos específicos de alunos. Estudantes do sexo feminino com formação secundária profissionalizante ou, estudantes do sexo feminino oriundas de escolas privadas apresentam rendimento superior à média geral dos investigados. Observouse, também, que a repetência nestas disciplinas é mais expressiva entre os desistentes, o que sugere uma correlação entre evasão e repetência.

O que foi até aqui apresentado leva-nos a supor que, para o curso estudado, os fatores associados ao estudante, tais como desinteresse pelo estudo ou falta de base, não são preponderantes para a evasão. Tal resultado guarda coerência com os descrito por Cunha e colaboradores $^{22}$, ao reportarem aspectos relacionados à evasão no curso de Química da UnB. Segundo esses autores, os estudantes estariam atribuindo sua evasão a aspectos tais como insatisfação com o curso, conflitos quanto à escolha adequada de curso, decepção com a universidade, etc. Esses mesmos aspectos, motivados, entre outros fatores, por currículo desmotivador, por práticas pedagógicas inadequadas, por dificuldades para a utilização de acervo bibliográfico e de recursos de informática, ou para ter acesso a professores fora do horário de aula, poderiam estar sendo relevantes, no caso do curso noturno de Química da UFC.

Há de se considerar ainda as severas restrições para aquisição de material permanente e de consumo e para a recomposição do corpo docente, que vêm sendo a realidade das IFES nos últimos anos. Tais dificuldades têm impacto negativo sobre o ensino e possivelmente contribuem para a evasão. Não faz parte do escopo desse trabalho pesquisar quais dos fatores considerados no parágrafo precedente e neste que estariam sendo prevalentes para a evasão. Entretanto, à luz dos resultados obtidos, é possível supor que modificações curriculares e alterações de procedimentos pedagógicos, associadas à melhoria das condições de recursos humanos e materiais disponíveis, poderiam ter consequiências positivas para o enfrentamento dos problemas de evasão observados no curso noturno de Química da UFC.

Como visto, diversos indicadores sugerem que o prestígio social do curso em estudo está em ascensão: aumento da concorrência, crescimento do percentual de alunos filhos de pais com mais anos de escolaridade, diminuição da idade média de ingresso, decréscimo nos índices de reprovação nas disciplinas do primeiro ano e aparente tendência de redução das taxas de evasão. Tal fato pode estar vinculado ao crescente aumento na oportunidade de trabalho para professores de ensino médio em Química, Física e Biologia que a Região Nordeste vem oferecendo nos últimos anos, tornando o curso de Licenciatura em Química um atrativo para profissionais em fase de profissionalização e/ou para profissionais já graduados em outras áreas de atuação.

Em termos regionais ${ }^{12,16}$, destaca-se que a matrícula nas IFES tem crescido mais acentuadamente nas Regiões Nordeste e CentroOeste, que registram aumentos de $14,5 \%$ e $10,8 \%$, respectivamente, no período de 1996-1999. No mesmo período, as universidades federais expandiram a matrícula em $26 \%$ no Nordeste ${ }^{12,16}$. Nota-se ainda, como resultado positivo, que a matrícula noturna teve um aumento mais expressivo na Região Nordeste, com a abertura de 6.895 vagas, representando em crescimento de $33,5 \%$. Um dos principais indicadores de eficiência nos sistemas educacionais é a proporção de concluintes em relação ao número de ingressantes, em dado período de tempo. A melhoria deste indicador sinaliza para uma redução das taxas de evasão e para um aumento das taxas de conclusão.
Um fato a ponderar, no entanto, relaciona-se aos estudos feitos por Gatti ${ }^{3}$. Na concepção da autora, nos cursos de Licenciatura com maiores exigências curriculares, a evasão é mais alta. A autora ${ }^{3}$ acredita que, se por um lado se pode pensar que a evasão se dá por problemas relativos à forma como os cursos são oferecidos (mais exigentes), por outro, a associação deste fator às péssimas perspectivas de carreira (baixos salários, valorização social, etc) possibilita a potencialização da deserção.

Embora não se possa descartar a contribuição desses fatores para o caso em estudo, deve ser observado que quase cinco anos se passaram desde a publicação do trabalho citado. Nesse período ocorreram mudanças expressivas no cenário do ensino superior brasileiro, entre as quais se destacam a entrada em vigor de uma nova LDB, que requer formação superior para os professores do ensino fundamental e do ensino médio, e o grande aumento no número de concluintes da escola média, quase todo ele verificado na rede pública.

Em uma última etapa deste trabalho, investigamos a continuidade destes estudantes junto aos cursos de Mestrado (área de concentração: Química Orgânica e Inorgânica) na UFC. Neste caso em particular, enquadramos os estudantes graduados nos três cursos de Química oferecidos pelo Centro de Ciências da UFC: Licenciatura em Química (diurno/noturno), Bacharelado em Química (diurno) e Química Industrial (diurno). Observamos que nestes cinco últimos anos, 50 estudantes deram entrada nos referidos cursos de pós-graduação. Apenas um pequeno percentual, 14\%, foi proveniente de outros cursos que não os da área de Química; 24\% foram oriundos dos cursos de Licenciatura em Química, 34\% do curso de Química Industrial e 28\% do curso de Bacharelado em Química.

Tais observações nos conduzem a acreditar que, além dos objetivos propostos pelo curso de Licenciatura em Química, nossos estudantes estão buscando uma melhoria em suas qualificações, inscrevendo-se nos programas de pós-graduação existentes na própria Universidade.

Neste contexto, no entanto, pode-se perceber que os Licenciados fogem, de algum modo, do objetivo principal de seu curso, que é atuar no ensino básico, optando por encaminhar-se para mestrado e doutorado da área específica, no caso química, objetivando talvez, o magistério superior e a pesquisa pura.

Um ponto a considerar é que, talvez pela estrutura do próprio curso de graduação, pelo tipo de currículo oferecido, pelas exigências de melhor qualificação, pela procura de maiores salários e status (atualmente é o que a Universidade oferece), o aluno se sinta atraído a fazer Mestrado e Doutorado na área específica de química, visando maior especialização e desinteressando-se por um maior preparo didático-pedagógico. É interessante enfatizar, no entanto, que o Programa de Pós-Graduação em Química Inorgânica da UFC, tem implementado a formação didático/pedagógica de seus estudantes, através do Estágio de Docência ${ }^{23}$ ( 2 créditos para Mestrado e 4 créditos para Doutorado) .

No entanto, a entrada dos estudantes nos cursos de mestrado e doutorado, não implica em aperfeiçoamento da formação global. É preciso ter em mente que a formação docente deve abranger conhecimentos sistematizados tanto científicos como filosóficos e tecnológicos, como um todo.

\section{CONSIDERAÇÕES FINAIS}

Este trabalho teve por objetivo mostrar os resultados de um estudo sobre o curso de Licenciatura em Química noturno da UFC, desde sua implantação (1995) até o ano de 2000, na tentativa de verificar seu andamento, bem como o desempenho de seus estudantes. Não foi possível, no entanto, se chegar a conclusões concretas posto tratar-se de um curso novo, embora se possa tecer algumas considerações. 
Com base no estudo, vários indicadores apontam para o aumento do prestígio social do curso em questão: verificou-se um crescimento da concorrência; a idade média de ingresso no curso diminuiu; o número de alunos filhos de pais com maior escolaridade aumentou; os índices de reprovação nas disciplinas do primeiro ano de curso decresceram; há uma aparente tendência de redução das taxas de evasão e aumento nas taxas de conclusão.

Embora o estudo, por sua provisoriedade, não trace um perfil completo, mostra indícios de que, mesmo com um quadro de melhoria no decorrer dos anos, o curso de Licenciatura em Química noturno da UFC ainda apresenta problemas, à semelhança de muitos no país. Pode-se intuir que mudanças curriculares, modificações nos procedimentos pedagógicos, melhores condições de recursos humanos e materiais disponíveis (materiais didáticos, equipamentos, reagentes, etc) bem como uma redefinição política e social do papel das licenciaturas nas universidades contribuiriam positivamente para enfrentar as dificuldades.

\section{AGRADECIMENTOS}

As autoras agradecem à Pró-Reitoria de Planejamento Coordenadoria de Estatística e Informática; ao Núcleo de Processamento de Dados, à Comissão do Concurso do Vestibular; à Coordenação do Curso de Química e à Secretaria de Pós-Graduação do Departamento de Química Orgânica e Inorgânica, da Universidade Federal do Ceará, pelo apoio recebido.

\section{REFERÊNCIAS E NOTAS}

1. Mello, G. N.; Cidadania e Competitividade: Desafios Educacionais do Terceiro Milênio, Cortez: São Paulo, 1996.

2. Pereira, J. E. D.; Anais do Encontro Nacional de Didática e Prática de Ensino, Águas de Lindóia, Brasil, 1998, 1, 341; Mortimer, E. F.; Pereira, J. E. D.; Educação em Revista 1999, 30, 107.

3. Gatti, B.; Formação de Professores e Carreira: Problemas e Movimentos de Renovação, Autores Associados: Campinas, 1997.

4. Diário Oficial da União 26 janeiro de1961, 349.

5. De acordo com informações obtidas junto a Pró-Reitoria de Graduação da UFC, cada crédito equivale a $15 \mathrm{~h} /$ aula.

6. Projeto Pedagógico do Curso de Química, Coordenação do Curso de Química, Universidade Federal do Ceará, Centro de Ciências, 1999.

7. Carneiro, C. C. B. S.; $2^{\circ}$ Encontro Latino Americano de Ensino em Química, $10^{\circ}$ Encontro Nacional de Ensino em Química e $20^{\circ}$ Encontro de Debates sobre o Ensino de Química no Rio Grande do Sul, Porto Alegre, Brasil, 2000.

8. Freitas, L. P.; Plano Nacional de Graduação - Fortaleza, Universidade de Fortaleza, 1999.
9. Face à fase de ajuste curricular, característica de mudanças emergentes, deve-se ressaltar que neste período de transição (especialmente em 2000/ 2), foram registrados alguns problemas com alunos que necessitaram integralizar as $300 \mathrm{~h}$ obrigatórias de Prática de Ensino, em período não regular, para a obtenção do grau de Licenciado em Química.

10. Manual do Estudante, Pró-Reitoria de Graduação, Universidade Federal do Ceará, 2000.

11. A transferência configura-se quando o estudante de outra instituição de ensino transfere seu vínculo para a UFC, podendo ser facultativa ou obrigatória. A Admissão por Convênio decorre de convênios bilaterais do Brasil com países da América Latina e da África e resulta na admissão de estudantes estrangeiros. A Admissão de Graduado é facultada a profissionais já graduados, para aproveitamento das vagas ociosas. A Mudança de Curso é procedimento interno, pelo qual o estudante troca de curso, sem necessidade de novo vestibular. A Reopção é caracterizada quando o estudante obtém uma classificação no vestibular, que não o habilita a uma vaga no curso de opção, mas em outro curso de área correlata em que exista vaga remanescente.

12. http://www.mec.gov.br/nivemod/educsupe.shtm, acessada em Setembro 2001; http://www.inep.gov.br/noticias/news, acessada em Setembro 2001.

13. Em função disso ${ }^{12}$, apenas $7,7 \%$ da população brasileira de 20 a 24 anos freqüentam o ensino superior, uma das menores taxas do mundo. Este quadro é conseqüência de um dos principais problemas da educação básica: as elevadas taxas de distorção série/idade, de $46,5 \%$ no ensino fundamental e de $53,9 \%$ no ensino médio. Cerca de 8,5 milhões de alunos do ensino fundamental têm 15 anos ou mais de idade e deveriam estar cursando o nível médio. Mais de 3,7 milhões de alunos do ensino médio possuem 18 anos ou mais de idade e poderiam estar matriculados na universidade.

14. Archangelo, J. Em Formação do Educador: Avaliação Institucional, Ensino e Aprendizagem; Bicudo, M. A. V.; Silva Jr., C. A., orgs.; 1999, vol. 4, ed. UNESP: São Paulo, 1999.

15. Braga, M. M.; Miranda-Pinto, C. O. B.; Cardeal, Z. L.; Quim. Nova 1997, $20,438$.

16. http://www.ceara.gov.br/evo, acessada em Setembro 2001.

17. http://www.al.ce.gov.br/cpi/Fundef, acessada em Setembro 2001.

18. Silva, R. R.; Tunes, E.; Pachá, L. C. L.; Junqueira, R. M. P.; Quim. Nova 1995, 18, 210.

19. Desligamento Voluntário: forma de exclusão concedida ao aluno que, por iniciativa própria, tenha desistido do seu vínculo com a Universidade em determinado curso. Abandono: forma de exclusão automática do cadastro discente, ao aluno que, durante dois períodos letivos consecutivos, não tenha efetivado matrícula em disciplinas. Não Cumprimento da Condição: forma de exclusão, ao aluno que, tendo sido identificado como provável desligado por rendimento acadêmico ou por tempo de permanência, não tenha cumprido, no decorrer do(s) período(s) fixado(s), a condição que lhe foi imposta pelos órgãos colegiados.

20. Reopção: ocorre quando o estudante muda de curso, sem a necessidade de um novo vestibular. Transferência: quando o estudante transfere seu vínculo com o curso de Química para outra Instituição de ensino superior. Desistênci:a: qualquer outro motivo que tenha ocasionado a evasão.

21. Vidal, R. M. B.; Mazzetto, S. E.; Segundas Jornadas Internacionales de Ensenãnza Universitária de la Química, Montevideo, Uruguay, 2001.

22. Cunha, A. M.; Tunes, E.; Silva, R. R.; Quim. Nova 2001, 24, 262.

23. Feitosa, J. P. A.; Quim. Nova 2002, 25, 153 